\title{
Gastrodin represses hydrogen peroxide-induced oxidative stress in retinal pigment epithelial cells through p38MAPK/iNOS pathway
}

\author{
Xingli Zhou ${ }^{1}$ and Ximing Zhao ${ }^{2 *}$ \\ ${ }^{1}$ Department of Ophthalmology, Affiliated Hospital of Qinghai University, Xining, Qinghai, China; ${ }^{2}$ Department of Joint \\ Bone, Affliated Hospital of Qinghai University, Xining, Qinghai, China
}

"Corresponding author: Ximing Zhao, Department of Joint Bone, Affiliated Hospital of Qinghai University, No. 29 Tongren Road, Xining, Qinghai, China. Email: z_xm123@163.com

Received: 16 September 2021; Accepted: 15 October 2021; Published: 26 November 2021

(c) 2021 Codon Publications

OPEN ACCESS @) (1) ORIGINAL ARTICLE

\begin{abstract}
Elevated reactive oxygen species (ROS) induce oxidative damage in retinal pigment epithelium (RPE) and contribute to the development of age-related macular degeneration (AMD). Gastrodin plays an antioxidant role in distinct diseases, such as epilepsy, cerebral ischemia, Alzheimer's disease, and cardiovascular diseases. However, the function of gastrodin in AMD remains unclear. Human RPE (ARPE-19) cells were incubated with $300 \mu \mathrm{M}$ hydrogen peroxide $\left(\mathrm{H}_{2} \mathrm{O}_{2}\right)$ for 24 hours. The results showed that $\mathrm{H}_{2} \mathrm{O}_{2}$ decreased cell viability and promoted the cell apoptosis of ARPE-19 cells. $\mathrm{H}_{2} \mathrm{O}_{2}$-induced ARPE-19 cells were then treated with different concentrations of gastrodin. Gastrodin increased cell viability of $\mathrm{H}_{2} \mathrm{O}_{2}$-induced ARPE-19 cells, suppressed the cell apoptosis of $\mathrm{H}_{2} \mathrm{O}_{2}$-induced ARPE-19 cells with reduced B-cell lymphoma (Bcl)-2 like protein (Bax), and enhanced Bcl-2. The levels of ROS were enhanced, malondialdehyde (MDA) was up-regulated, and superoxide dismutase (SOD) and glutathione (GSH) were down-regulated in $\mathrm{H}_{2} \mathrm{O}_{2}$-induced ARPE-19 cells. However, gastrodin reduced the levels of ROS and MDA and elevated SOD and GSH in $\mathrm{H}_{2} \mathrm{O}_{2}$-induced ARPE-19 cells. Furthermore, $\mathrm{H}_{2} \mathrm{O}_{2}$-induced increase of inducible nitric oxide synthase (iNOS) and p-p38 proteins in ARPE-19 was reversed by gastrodin. In conclusion, gastrodin exerted antiapoptotic and antioxidant capacities to protect against $\mathrm{H}_{2} \mathrm{O}_{2}$-induced oxidative stress in RPE, thereby acting as a potential agent for managing AMD.
\end{abstract}

Keywords: age-related macular degeneration; apoptosis; gastrodin; hydrogen peroxide; inducible nitric oxide synthase; oxidative stress; retinal pigment epithelium

\section{Introduction}

Age-related macular degeneration (AMD) is a progressive and degenerative eye disease that affects the macular area of the retina (Brown et al., 2018). It is the leading cause of permanent visual impairment and severe blindness in an aging world (Brown et al., 2018). Although the pathogenesis of AMD is not fully understood, dysfunction of retinal pigment epithelium (RPE) regulates retinal integrity and viability, thereby playing a central role in the progression of AMD (Somasundaran et al., 2020). Pathological events, including cell polarity and interactions, apoptosis and autophagy, and oxidative stress and inflammation, are implicated in the abnormal function of RPE and induce the progression of AMD (Yang et al., 2021). Cell, gene, and drug therapies that protect RPE against damages are beneficial for the prevention of AMD (Yang et al., 2021). For example, preclinically stem cell-derived RPE is used for human retinal degenerative diseases treatment (Yang et al., 2021). Drugs induced 
expression of nuclear factor erythroid 2-related factor 2 (Nrf2) to ameliorate retinal degeneration (Campello et al., 2020).

Increasing evidence has shown that an elevated level of reactive oxygen species (ROS) is associated with retinal diseases, including AMD, diabetic retinopathy, and glaucoma (Ruan et al., 2020). Accumulation of ROS results in inflammation, neuron degeneration, and vascular endothelial dysfunction in the retina (Ruan et al., 2020). Repression of oxidative stress might be effective in AMD treatment (Zhou et al., 2020).

Gastrodin is the bioactive constituent of the orchid plant Gastrodia elata Blume and has been widely used as a traditional Chinese medicine with anxiolytic, sedative, analgesic, anti-inflammatory, anticonvulsant, and antioxidant properties (Yan et al., 2019). For example, gastrodin stimulated osseointegration and suppressed osteoclastogenesis to prevent osteolytic diseases (Zhou et al., 2017). It reduced chronic ischemia-induced oxidative stress and improved cognitive impairment in rats with vascular dementia (Li and Zhang, 2015). Moreover, 14-3-3 $\eta$-induced anoxia/reoxygenation injury in cardiomyocytes was repressed by gastrodin (Zhu et al., 2018). Gastrodin retarded retinal microglia activation and reduced the loss of retinal ganglion cells to exert neuroprotective effect against retinal neurodegenerative diseases (Wang et al., 2017). Gastrodin repressed the high glucose-induced cell apoptosis of human retinal endothelial cell (Zhang et al., 2018) and it attenuated hydrogen peroxide $\left(\mathrm{H}_{2} \mathrm{O}_{2}\right)$ and $\mathrm{N}$-methyl-D-aspartate. Leading to decreased cell viability and increased ROS levels in retinal ganglion cells, thus ameliorating glaucoma-related retinal degeneration (Molinari et al., 2021). However, the role and related mechanism of gastrodin in AMD is still unclear.

This study investigates the effects of gastrodin on cell viability, apoptosis, and oxidative stress of $\mathrm{H}_{2} \mathrm{O}_{2}$-induced ARPE-19.

\section{Materials and Methods}

\section{Cell culture and treatment}

Human RPE cells (ARPE-19) were acquired from Procell Life Science \& Technology (Wuhan, China) and cultured in Dulbecco's modified Eagle's medium (Gibco, Carlsbad, CA, USA) containing 10\% fetal bovine serum (Invitrogen, Shanghai, China). Cells were treated with 10, 50, or 100 $\mu \mathrm{M}$ gastrodin (Sigma-Aldrich, St Louis, MO, USA) or exposed to $300 \mu \mathrm{M} \mathrm{H}_{2} \mathrm{O}_{2}$ (Sigma-Aldrich) for 24 hours. Later the cells treated with $\mathrm{H}_{2} \mathrm{O}_{2}$ were reincubated with 10 or $50 \mu \mathrm{M}$ gastrodin for 24 hours, and cells with $80 \%$ confluence were used for the functional experiments.

\section{Measurement of oxidative stress}

The ARPE-19 cells after $\mathrm{H}_{2} \mathrm{O}_{2}$ and gastrodin treatment were incubated with dichlorofluorescein-diacetate (0.5 $\mu \mathrm{M}$; DCFH-DA; Sigma-Aldrich) for 0.5 hours, and then analyzed by FACSCalibur flow cytometer (Becton Dickinson Biosciences, San Jose, CA, USA) to determine fluorescence intensity of dichlorodihydrofluorescein. The enzyme-linked immunosorbent assay kits (Nanjing KeyGen Biotech Co., Ltd., Nanjing, China) were used to measure the levels of malondialdehyde (MDA), superoxide dismutase (SOD), and glutathione (GSH).

\section{Cell viability and apoptosis assays}

The ARPE-19 cells after $\mathrm{H}_{2} \mathrm{O}_{2}$ and gastrodin treatment were seeded in a 96-well plate for 24 hours and treated with cell counting kit-8 solution $(10 \mu \mathrm{L}$; Beyotime, Beijing, China) for 2 hours. Absorbance at $450 \mathrm{~nm}$ was measured via a microplate reader (Sigma-Aldrich). ARPE-19 cells were harvested and resuspended in the binding buffer from Annexin V-FITC/ propidium iodide (PI) apoptosis detection kit (Becton Dickinson Biosciences). Following labeling with PI and annexin V-FITC, cells were analyzed under the flow cytometer.

\section{Western blot}

ARPE-19 cells were lysed in Radioimmunoprecipitation assay lysis buffer (Beyotime), and the protein samples were isolated and separated using $10 \%$ sodium dodecyl sulfate-polyacrylamide gel electrophoresis. The samples were then transferred onto a nitrocellulose membrane. The membranes were blocked and probed with specific antibodies: anti-B-cell lymphoma (Bcl)-2 like protein (Bax) and anti-Bcl-2 (1:2000, Abcam, Cambridge, UK), anti-p38 and anti-p-p38 (1:3000, Abcam), and anti-inducible nitric oxide synthase (iNOS) and anti-glyceraldehyde 3-phosphate dehydrogenase i (1:4000, Abcam). The protein bands were visualized using chemiluminescence (SigmaAldrich) after incubation with horseradish peroxidaseconjugated secondary antibody (1:5000, Abcam) and tetramethylbenzidine.

\section{Statistical analysis}

All the data with at least triple replicates were expressed as mean \pm standard error of the mean and analyzed by student's t-test or one-way analysis of variance in SPSS software (SPSS, Chicago, IL, USA). P < 0.05 was considered statistically significant. 


\section{Results}

\section{Gastrodin increased cell viability of $\mathrm{H}_{2} \mathrm{O}_{2}$-induced ARPE-19 cells}

The ARPE-19 cells were incubated with different concentrations of gastrodin to investigate the cytotoxic effects of gastrodin on RPE. Gastrodin lower than 50 $\mu \mathrm{M}$ had no significant effect on cell viability of ARPE19 cells (Figure $1 \mathrm{~A}$ ), and $100 \mu \mathrm{M}$ gastrodin reduced $20 \%$ of cell viability in ARPE-19 (Figure 1A). $\mathrm{H}_{2} \mathrm{O}_{2}$ induced ARPE-19 cells decreased the cell viability (Figure 1B), whereas a gastrodin enhanced cell viability of $\mathrm{H}_{2} \mathrm{O}_{2}$ induced ARPE-19 cells in a dosage-dependent manner (Figure 1B). These results suggested the protective effect of gastrodin against $\mathrm{H}_{2} \mathrm{O}_{2}$-induced cytotoxicity in ARPE-19.

\section{Gastrodin decreased oxidative stress of $\mathrm{H}_{2} \mathrm{O}_{2}$-induced ARPE-19 cells}

The $\mathrm{H}_{2} \mathrm{O}_{2}$-induced ARPE-19 cells showed ROS accumulation by the the presence of increased dichlorodihydrofluorescein fluorescence intensity. But the addition of gastrodin deteriorated the ROS levels in these cells in a dosage-dependent manner (Figure $2 \mathrm{~A}$ and $2 \mathrm{~B}$ ). $\mathrm{H}_{2} \mathrm{O}_{2}-$ treatment increased the levels of MDA (Figure 2C), decreased SOD (Figure 2D) and GSH (Figure 2E) in ARPE19 cells, and this was reversed by gastrodin, demonstrating its antioxidant effect on $\mathrm{H}_{2} \mathrm{O}_{2}$-induced ARPE-19 cells.
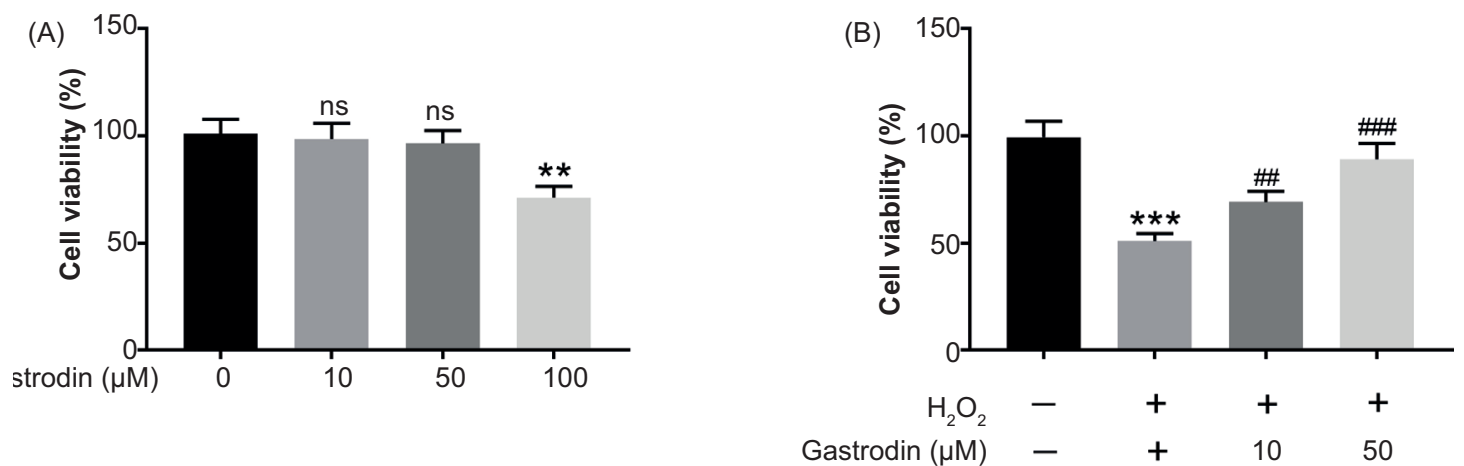

Figure 1. Gastrodin increased cell viability of hydrogen peroxide-induced ARPE-19 cells. (A) Gastrodin lower than $50 \mu \mathrm{M}$ had no significant effect on cell viability and $100 \mu \mathrm{M}$ gastrodin reduced $20 \%$ of cell viability in ARPE-19 cells. (B) Gastrodin enhanced cell viability of hydrogen peroxide-induced ARPE-19 cells in a dosage dependent manner. ${ }^{* *} P<0.01,{ }^{* * *} P<0.001$. $@ P<0.05, \# P<0.01$, and \#\#P 0.001.

(A)

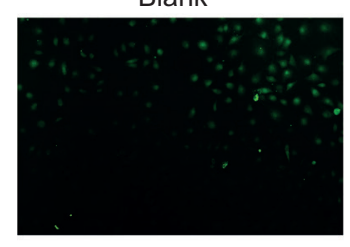

$\mathrm{H}_{2} \mathrm{O}_{2}+$ Gastrodin $(10 \mu \mathrm{M})$

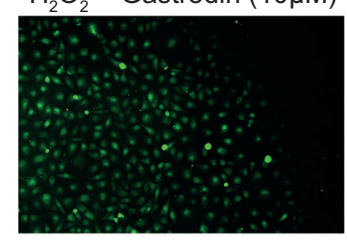

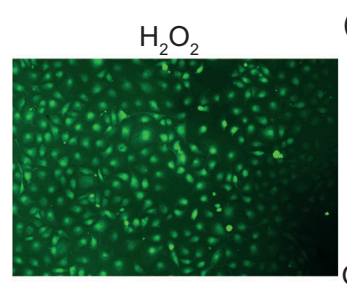

$\mathrm{H}_{2} \mathrm{O}_{2}+$ Gastrodin $(50 \mu \mathrm{M})$

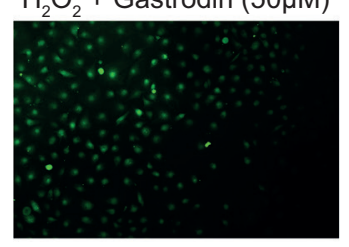

(B)

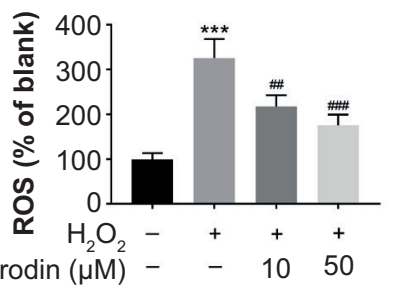

(D)

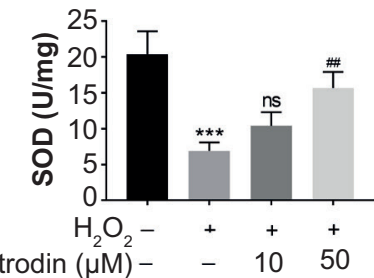

(C)

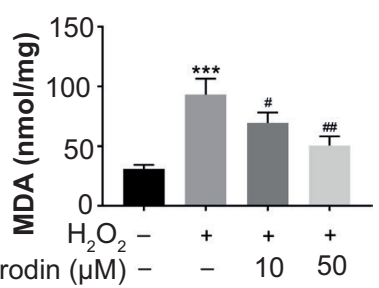

(E)

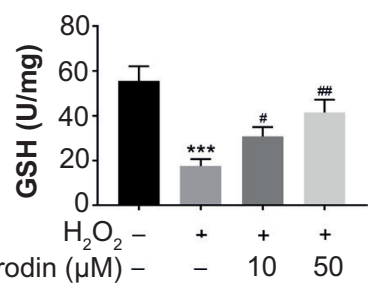

Figure 2. Gastrodin decreased oxidative stress of hydrogen peroxide (H2O2)-induced ARPE-19 cells. (A) Gastrodin reduced reactive oxygen species of $\mathrm{H}_{2} \mathrm{O}_{2}$-induced ARPE-19 in a dosage dependent manner. (B) The relative levels of reactive oxygen species in each group are shown. Gastrodin reduced (C) malondialdehyde of $\mathrm{H}_{2} \mathrm{O}_{2}$-induced ARPE-19 in a dosage dependent manner, and enhanced (D) superoxide dismutase and (E) glutathione of $\mathrm{H}_{2} \mathrm{O}_{2}$-induced ARPE-19 in a dosage dependent way. ${ }^{* * *} P<0.001, \# P<0.05, \# P<0.01$, and \#\#P<0.001. 
Gastrodin repressed cell apoptosis of $\mathrm{H}_{2} \mathrm{O}_{2}$-induced ARPE-19 cells

Cell apoptosis of ARPE-19 cells was promoted by $\mathrm{H}_{2} \mathrm{O}_{2}$ treatment (Figure $3 \mathrm{~A}$ ), whereas gastrodin reduced cell apoptosis of $\mathrm{H}_{2} \mathrm{O}_{2}$-induced ARPE-19 cells in a dosagedependent manner (Figure 3A). Gastrodin also attenuated $\mathrm{H}_{2} \mathrm{O}_{2}$-induced increase in $\mathrm{Bax}$ and $\mathrm{Bcl}-2$ decrease in ARPE-19 (Figure 3B), indicating the antiapoptotic effect of gastrodin on $\mathrm{H}_{2} \mathrm{O}_{2}$-induced ARPE- 19 .

\section{Gastrodin suppressed activation of p38MAPK/iNOS in $\mathrm{H}_{2} \mathrm{O}_{2}$-induced ARPE-19 cells}

Protein expression of p38 was not affected either by $\mathrm{H}_{2} \mathrm{O}_{2}$ or gastrodin treatment in ARPE-19 cells (Figure 4). However, p-p38 was upregulated in $\mathrm{H}_{2} \mathrm{O}_{2}$-induced ARPE-19 cells and down-regulated post gastrodin treatment (Figure 4). Moreover, the increased expression of iNOS in $\mathrm{H}_{2} \mathrm{O}_{2}$-induced ARPE-19 cells was restored by gastrodin (Figure 4), revealing the suppressive effect of
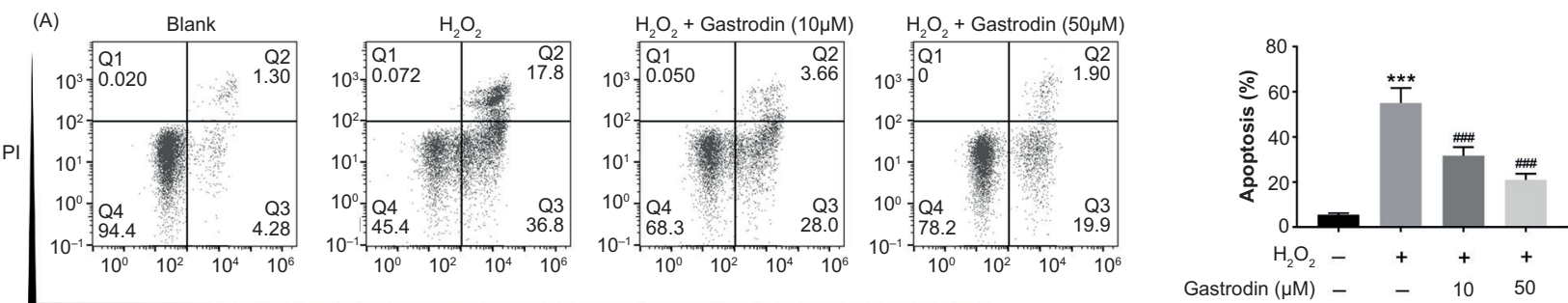

(B)
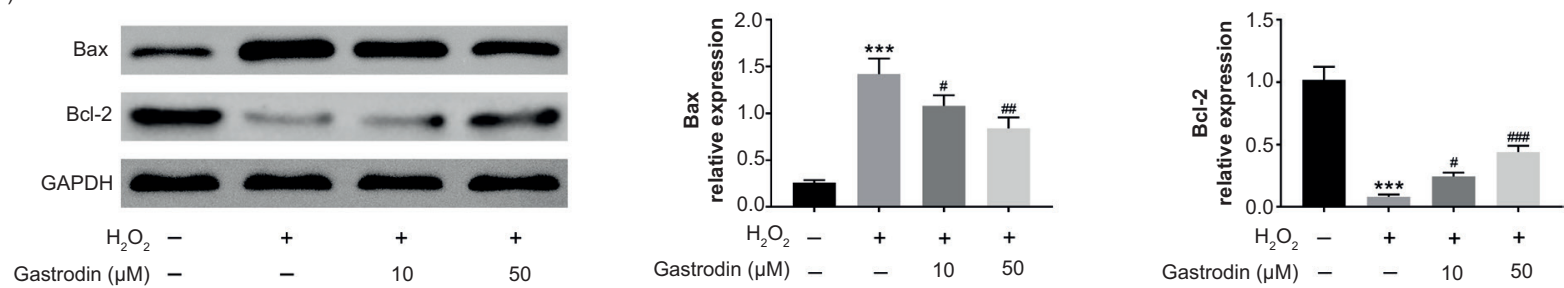

Figure 3. Gastrodin repressed cell apoptosis of hydrogen peroxide $\left(\mathrm{H}_{2} \mathrm{O}_{2}\right)$-induced ARPE-19 cells. (A) Gastrodin suppressed cell apoptosis of $\mathrm{H}_{2} \mathrm{O}_{2}$-induced ARPE-19 in a dosage dependent manner. (B) Gastrodin enhanced B-cell lymphoma (Bcl)-2 expression and reduced $\mathrm{B}$-cell lymphoma $(\mathrm{Bcl})-2$ like protein $(\mathrm{Bax})$ of $\mathrm{H}_{2} \mathrm{O}_{2}$-induced ARPE-19 cells in a dosage dependent manner. ${ }^{* * *} P<0.001, \# P<0.05, \# P<0.01$, and \#\#P 0.001 .
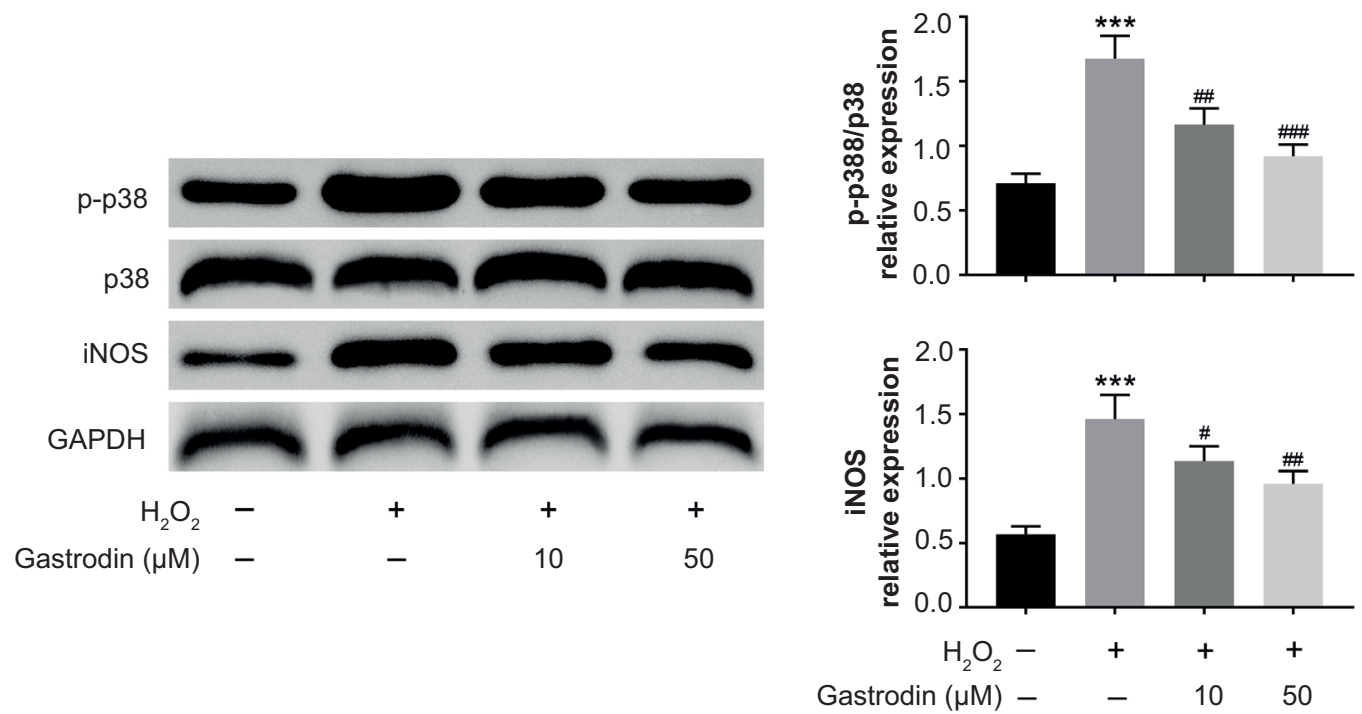

Figure 4. Gastrodin suppressed activation of p38MAPK/iNOS in hydrogen peroxide-induced ARPE-19 cells. Gastrodin reduced p-p38 and iNOS expression of hydrogen peroxide -induced ARPE-19 in a dosage dependent manner. The relative expression of p-p38/p38 and iNOS are shown on the right. ${ }^{* *} P<0.001, \# P<0.05, \# P<0.01$, and \#\#P $<0.001$. 
gastrodin on p38MAPK/iNOS signaling in $\mathrm{H}_{2} \mathrm{O}_{2}$-induced ARPE-19 cells.

\section{Discussion}

RPE is a postmitotic polarized epithelial cell. They are present between choroid and photoreceptors and play the role of a caretaker in the function and health of the photoreceptors (Taylor et al., 2021). Abnormal functioning of RPE underlies acquired and inherited diseases, such as AMD, which can lead to permanent blindness (Taylor et al., 2021). Diabetes or degenerative retinopathy induces excessive accumulation of ROS and reduces the antioxidant levels in RPE, thus leading to oxidative damage and retinal dysfunction (Yang et al., 2021). Administration of antioxidant nutrients reduced the risk for AMD (Raniga and Elder, 2009). Therefore, traditional Chinese herbs with antioxidant capacity are widely used in the clinical prevention of AMD (Jin et al., 2018; Li et al., 2021). Gastrodin, isolated from Gastrodia elata Blume, exerted antioxidant effect against retinal neurodegenerative diseases (Wang et al., 2017), high glucose-induced retinal endothelial cell apoptosis (Zhang et al., 2018), and glaucoma-related retinal degeneration (Molinari et al., 2021). This study investigated the role of gastrodin in AMD-associated RPE dysfunction.

$\mathrm{H}_{2} \mathrm{O}_{2}$ is generated in RPE through the photoreceptor outer segments phagocytosis, photoexcited pigment lipofuscin, or light irradiation of pigment melanin (Cia et al., 2014). The activity of catalases that neutralize $\mathrm{H}_{2} \mathrm{O}_{2}$ was reduced in patients with AMD, and accumulation of $\mathrm{H}_{2} \mathrm{O}_{2}$ in RPE during aging is strongly related to AMD (Cia et al., 2014). Therefore, $\mathrm{H}_{2} \mathrm{O}_{2}$-induced RPE damage was widely used as an in-vitro cell model of AMD (Cia et al., 2014). This study showed that $\mathrm{H}_{2} \mathrm{O}_{2}$ induced a decrease in cell viability of ARPE-19 cells and promoted cell apoptosis, demonstrating cytotoxicity effect on RPE. Catechin isolated from green tea is epigallocatechin gallate, suppresses $\mathrm{H}_{2} \mathrm{O}_{2}$-induced oxidative stress of RPE (Cia et al., 2014). This study results showed that gastrodin protected ARPE-19 against $\mathrm{H}_{2} \mathrm{O}_{2}$ induced cytotoxicity through increased cell viability and decreased cell apoptosis. The study by Yang et al. (2021) has shown that RPE in patients with AMD exhibited higher levels of endoplasmic reticulum stress, autophagy, and apoptosis than normal cells, leading to an increased number of autophagosomes and decreased mitochondrial activity in RPE cells isolated from AMD donors (Golestaneh et al., 2017). Strategy to reduce cell apoptosis of AMD-associated RPE might be effective for the prevention of AMD (Arumugam et al., 2019). Therefore, gastrodin that exerted an antiapoptotic effect against $\mathrm{H}_{2} \mathrm{O}_{2}$-induced RPE can be regarded as a potential strategy for AMD treatment.
RPE with high metabolic activity enriches mitochondria and contributes to the primary production of ROS (Apte, 2021). Excessive accumulation of ROS results in structural damage and changes in RPE during the progression of AMD (Apte, 2021). Therefore, therapeutic strategies to reduce oxidative stress are effective in reducing retinal damage associated with AMD (Rohowetz et al., 2018). In this study, $\mathrm{H}_{2} \mathrm{O}_{2}$-induced ARPE-19 cells showed an increased ROS and MDA and reduced SOD and GSH, thus promoting oxidative stress. A previous study has shown that gastrodin attenuates cell viability and increases ROS levels in $\mathrm{H}_{2} \mathrm{O}_{2}$-induced retinal ganglion cells (Molinari et al., 2021). In this study, the levels of ROS and MDA in $\mathrm{H}_{2} \mathrm{O}_{2}$-induced ARPE-19 cells were down-regulated by gastrodin, whereas SOD and GSH were upregulated, indicating an antioxidant effect on AMD-associated RPE. Inflammatory response of RPE was also implicated in the pathogenesis of AMD (Hytti et al., 2021), and suppression of inflammation prevented the progression of AMD (Mao et al., 2017). Since gastrodin repressed spinal synaptic potentiation and protected against chronic inflammation (Xiao et al., 2016), it can also exert an anti-inflammatory effect against $\mathrm{H}_{2} \mathrm{O}_{2}-$ induced RPE in AMD, which needs to be the topic of interest in future studies.

Dysregulated metabolic pathways involved in mitochondrial dysfunction and disintegration, cytoplasmic glycogen accumulation, ROS production, and autophagy function are reported to be the major contributors to AMD pathophysiology (Zhang et al., 2020). Mitogen-activated protein kinase (MAPK) signaling is associated with proliferation, apoptosis, and differentiation of RPE, and is regarded as the potential target for AMD (Kyosseva, 2016). Oxidative damage of RPE is seen to activate MAPK signaling pathways and contribute to RPE degeneration during the development of AMD (Chan et al., 2015). Activation of p38 MAPK was also involved in linking oxidative stress and the production of proinflammatory cytokines in RPE (Fernandes et al., 2008). Suppression of the MAPKs pathway protected against oxidative stress-induced damage in RPE (Chen et al., 2018). Gastrodin repressed oxidative stress in 1-methyl-4-phenylpyridinium-induced dopaminergic cells through inactivation of p38 MAPK (Jiang et al., 2014). Here, they also reduced protein expression of p-p38 in $\mathrm{H}_{2} \mathrm{O}_{2}$-induced RPE, thereby repressing activation of p38 MAPK. Moreover, iNOS is the pivotal enzyme for the synthesis of nitric oxide, and its excessive activity can lead to oxidative stress (Song et al., 2013). p38 MAPK/iNOS promoted the production of nitric oxide in high glucose-induced RPE (Yuan et al., 2008), and blocking of p38MAPK/iNOS pathway alleviated the oxidative stress (Song et al., 2013). Gastrodin has been reported to decrease the expression of iNOS by inactivation of MAPKs in lipopolysaccharide (LPS)-stimulated 
microglia (Dai et al., 2011). Protein expression of iNOS in $\mathrm{H}_{2} \mathrm{O}_{2}$-induced $\mathrm{RPE}$ was down-regulated by gastrodin treatment, suggesting that gastrodin protected against oxidative stress in RPE through inactivation of p38 MAPK/iNOS pathway.

In summary, gastrodin suppressed oxidative stress and retarded cell apoptosis in $\mathrm{H}_{2} \mathrm{O}_{2}$-induced RPE. The inactivation of the p38 MAPK/iNOS pathway was involved in the gastrodin-mediated suppression of oxidative stress in RPE. Therefore, gastrodin might be a novel strategy for the management of AMD. However, the effect of gastrodin on the $\mathrm{H}_{2} \mathrm{O}_{2}$-injured animal model should be the topic of interest in further studies.

\section{Funding}

This work was supported by the Youth fund of Qinghai University. (Grant No. 2019-QYY-15).

\section{Availability of Data and Materials}

All data generated or analyzed during this study are included in this published article.

\section{Competing interests}

The authors state that there are no conflicts of interest to disclose.

\section{Ethics approval}

Not applicable.

\section{Contribution of authors}

Xingli Zhou designed the study and supervised the data collection. Ximing Zhao analyzed and interpreted the data. Both the authors prepared the manuscript for publication, reviewed and approved the draft of the manuscript. All authors have read and approved the manuscript.

\section{References}

Apte, R.S., 2021. Age-related macular degeneration. New England Journal of Medicine 385(6): 539-547. https://doi.org/10.1056/ NEJMcp2102061

Arumugam, B., Palanisamy, U.D., Chua, K.H. and Kuppusamy, U.R., 2019. Protective effect of myricetin derivatives from Syzygium malaccense against hydrogen peroxide-induced stress in ARPE19 cells. Molecular Vision 25: 47-59.

Brown, C.N., Green, B.D., Thompson, R.B., den Hollander, A.I., Lengyel, I. and EYE-RISK Consortium, 2018. Metabolomics and age-related macular degeneration. Metabolites 9(1): 4. https:// doi.org/10.3390/metabo9010004

Campello B. L., Kutsyr, O., Noailles, A., Michalska, P., FernándezSánchez, L., et al. 2020. New Nrf2-inducer compound ITH12674 slows the progression of retinitis pigmentosa in the mouse model rd10. Cellular Physiology And Biochemistry 54(1):142159. https://doi.org/10.33594/000000210

Chan, C.-M., Huang, C.-H., Li, H.-J., Hsiao, C.-Y., Su, C.-C., Lee, P.-L., et al. 2015. Protective effects of resveratrol against UVA-induced damage in ARPE19 cells. International Journal of Molecular Sciences 16: 5789-5802. https://doi.org/10.3390/ ijms16035789

Chen, L., Liu, M., Luan, Y., Liu, Y., Zhang, Z., Ma, B., et al. 2018. BMP-6 protects retinal pigment epithelial cells from oxidative stress-induced injury by inhibiting the MAPK signaling pathways. International Journal of Molecular Medicine 42: 10961105. https://doi.org/10.3892/ijmm.2018.3675

Cia, D., Vergnaud-Gauduchon, J., Jacquemot, N. and Doly, M., 2014. Epigallocatechin gallate (EGCG) prevents $\mathrm{H} 2 \mathrm{O} 2$-induced oxidative stress in primary rat retinal pigment epithelial cells. Current Eye Research 39: 944-952. https://doi.org/10.3109/02713683.20 14.885532

Dai, J.-N., Zong, Y., Zhong, L.-M., Li, Y.-M., Zhang, W., Bian, L.-G., et al. 2011. Gastrodin inhibits expression of inducible NO synthase, cyclooxygenase- 2 and proinflammatory cytokines in cultured LPS-stimulated microglia via MAPK pathways. PLoS One 6: e21891-e. https://doi.org/10.1371/journal.pone.0021891

Fernandes, A.F., Zhou, J., Zhang, X., Bian, Q., Sparrow, J., Taylor, A., et al. 2008. Oxidative inactivation of the proteasome in retinal pigment epithelial cells. A potential link between oxidative stress and up-regulation of interleukin-8. Journal of Biological Chemistry 283: 20745-20753. https://doi.org/10.1074/jbc.M800268200

Golestaneh, N., Chu, Y., Xiao, Y.-Y., Stoleru, G.L. and Theos, A.C., 2017. Dysfunctional autophagy in RPE, a contributing factor in age-related macular degeneration. Cell Death and Disease 8: e2537-e. https://doi.org/10.1038/cddis.2016.453

Hytti, M., Korhonen, E., Hongisto, H., Kaarniranta, K., Skottman, H. and Kauppinen, A., 2021. Differential expression of inflammasomerelated genes in induced pluripotent stem-cell-derived retinal pigment epithelial cells with or without history of age-related macular degeneration. International Journal of Molecular Sciences 22: 6800. https://doi.org/10.3390/ijms22136800

Jiang, G., Hu, Y., Liu, L., Cai, J., Peng, C. and Li, Q., 2014. Gastrodin protects against $\mathrm{MPP}+$-induced oxidative stress by up regulates heme oxygenase-1 expression through $\mathrm{p} 38 \mathrm{MAPK} / \mathrm{Nrf2}$ pathway in human dopaminergic cells. Neurochemistry International 75: 79-88. https://doi.org/10.1016/j.neuint.2014.06.003

Jin, M., Dai, H., Zhang, X., Wang, Y., Han, M., Zhang, H., et al. 2018. A traditional Chinese patent medicine ZQMT for neovascular age-related macular degeneration: a multicenter randomized clinical trial. Current Molecular Medicine 18: 622-629. https:// doi.org/10.2174/1566524019666190107155311 
Kyosseva, S.V., 2016. Targeting MAPK signaling in age-related macular degeneration. Ophthalmology and Eye Disease 8: 23-30. https://doi.org/10.4137/OED.S32200

Li, Y., Liang, L., Snellingen, T., Xu, K., Gao, Y., Zhang, F., et al., 2021. Mingjing granule, a traditional Chinese medicine in the treatment of neovascular age-related macular degeneration: study protocol for a randomized controlled trial. Trials 22: 69. https:// doi.org/10.1186/s13063-021-05025-x

Li, Y. and Zhang, Z., 2015. Gastrodin improves cognitive dysfunction and decreases oxidative stress in vascular dementia rats induced by chronic ischemia. International Journal of Clinical and Experimental Pathology 8: 14099-14109. Available from: http:// europepmc.org/abstract/MED/26823723; https://europepmc. org/articles/PMC4713509; https://europepmc.org/articles/ PMC4713509?pdf=render

Mao, K., Shu, W., Qiu, Q., Gu, Q. and Wu, X., 2017. Salvianolic acid A protects retinal pigment epithelium from OX-LDLinduced inflammation in an age-related macular degeneration model. Discovery Medicine 23: 129-147. https://doi. org/10.1155/2017/6210694

Molinari, C., Ruga, S., Farghali, M., Galla, R., Fernandez-Godino, R., Clemente, N., et al. 2021. Effects of a new combination of natural extracts on glaucoma-related retinal degeneration. Foods 10: 1885. https://doi.org/10.3390/foods10081885

Raniga, A. and Elder, M., 2009. Dietary supplement use in the prevention of age-related macular degeneration progression. The New Zealand Medical Journal 122: 32-38.

Rohowetz, L.J., Kraus, J.G. and Koulen, P., 2018. Reactive oxygen species-mediated damage of retinal neurons: drug development targets for therapies of chronic neurodegeneration of the retina. International Journal of Molecular Sciences 19: 3362. https:// doi.org/10.3390/ijms19113362

Ruan, Y., Jiang, S., Musayeva, A. and Gericke, A., 2020. Oxidative stress and vascular dysfunction in the retina: therapeutic strategies. Antioxidants (Basel) 9: 761. https://doi.org/10.3390/ antiox 9080761

Somasundaran, S., Constable, I.J., Mellough, C.B. and Carvalho, L.S., 2020. Retinal pigment epithelium and age-related macular degeneration: a review of major disease mechanisms. Clinical and Experimental Ophthalmology 48: 1043-1056. https://doi. org/10.1111/ceo.13834

Song, Y., Liu, J., Zhang, F., Zhang, J., Shi, T. and Zeng, Z., 2013. Antioxidant effect of quercetin against acute spinal cord injury in rats and its correlation with the p38MAPK/iNOS signaling pathway. Life Sciences 92: 1215-1221. https://doi.org/10.1016/j. lfs.2013.05.007

Taylor, A.W., Hsu, S. and Ng, TF., 2021. The role of retinal pigment epithelial cells in regulation of macrophages/microglial cells in retinal immunobiology. Frontiers in Immunology 12: 724601. https://doi.org/10.3389/fimmu.2021.724.601

Wang, J.-W., Liu, Y.-M., Zhao, X.-F. and Zhang, H., 2017. Gastrodin protects retinal ganglion cells through inhibiting microglialmediated neuroinflammation in an acute ocular hypertension model. International Journal of Ophthalmology 10: 1483-1489.

Xiao, M.-M., Zhang, Y.-Q., Wang, W.-T., Han, W.-J., Lin, Z., Xie, R.-G., et al. 2016. Gastrodin protects against chronic inflammatory pain by inhibiting spinal synaptic potentiation. Scientific Reports 6: 37251. https://doi.org/10.1038/srep37251

Yan, J., Yang, Z., Zhao, N., Li, Z. and Cao, X., 2019. Gastrodin protects dopaminergic neurons via insulin-like pathway in a Parkinson's disease model. BMC Neuroscience 20: 31. https:// doi.org/10.1186/s12868-019-0512-x

Yang, S., Zhou, J. and Li, D., 2021. Functions and diseases of the retinal pigment epithelium. Frontiers in Pharmacology 12: 727870. https://doi.org/10.3389/fphar.2021.727870

Yuan, Z., Feng, W., Hong, J., Zheng, Q., Shuai, J. and Ge, Y., 2008. p38MAPK and ERK promote nitric oxide production in cultured human retinal pigmented epithelial cells induced by high concentration glucose. Nitric Oxide: Biology and Chemistry/ Official Journal of the Nitric Oxide Society 20: 9-15. https://doi. org/10.1016/j.niox.2008.09.001

Zhang, M., Jiang, N., Chu, Y., Postnikova, O., Varghese, R., Horvath, A., et al. 2020. Dysregulated metabolic pathways in age-related macular degeneration. Scientific Reports 10: 2464. https://doi.org/10.1038/s41598-020-59244-4

Zhang, T.H., Huang, C.M., Gao, X., Wang, J.W., Hao, L.L. and Ji, Q., 2018. Gastrodin inhibits high glucose-induced human retinal endothelial cell apoptosis by regulating the SIRT1/TLR4/ NF-kBp65 signaling pathway. Molecular Medicine Reports 17: 7774-7780. https://doi.org/10.3892/mmr.2018.8841

Zhou, F., Shen, Y., Liu, B., Chen, X., Wan, L. and Peng, D., 2017. Gastrodin inhibits osteoclastogenesis via down-regulating the NFATc1 signaling pathway and stimulates osseointegration in vitro. Biochemical and Biophysical Research Communications 484: 820-826. https://doi.org/10.1016/j. bbrc.2017.01.179

Zhou, J., Chen, F., Yan, A. and Xia, X., 2020. Madecassoside protects retinal pigment epithelial cells against hydrogen peroxideinduced oxidative stress and apoptosis through the activation of Nrf2/HO-1 pathway. Bioscience Reports 40: BSR20194347. https://doi.org/10.1042/BSR20194347

Zhu, M., Deng, W., Di, S., Qin, M., Liu, D. and Yi, B., 2018. Gastrodin protects cardiomyocytes from anoxia/reoxygenation injury by 14-3-3ๆ. Oxidative Medicine and Cellular Longevity 2018: 3685391. https://doi.org/10.1155/2018/3685391 